\title{
PENGARUH STRUKTUR MODAL, UKURAN PERUSAHAAN, LIKUIDITAS TERHADAP KINERJA KEUANGAN YANG DIMODERASI INFLASI
}

\author{
Cindhy Dahlia \\ Fakultas Magister Ekonomi Universitas Tarumanagara, Jakarta \\ Email: cindhydahlia@yahoo.com
}

\begin{abstract}
This study aims to obtain empirical evidence on the effect of capital structure, firm size, and liquidity on financial performance with inflation as moderating variable. The number of sample companies used in this study is 168 non financial companies period from the year 2012 to 2016. The result of this study indicates that capital structure has a significant negative effect on financial performance, firm size has a significant positive effect on financial performance, and liquidity has a non significant but positive effect of financial performance. Data were analyzed using panel data regression. Based on the analysis of panel data regression, we concluded that inflation serves as pure moderating variable between the impact of liquidity on financial performance.
\end{abstract}

Keywords: Capital Structure, Firm Size, Liquidity, Inflation, Financial Performance

\begin{abstract}
ABSTRAK
Penelitian ini bertujuan untuk mendapatkan bukti empiris mengenai pengaruh struktur modal, ukuran perusahaan, likuiditas terhadap kinerja keuangan yang dimoderasi oleh inflasi. Jumlah sampel perusahaan yang digunakan dalam penelitian ini adalah 168 perusahaan non keuangan tahun 2012 2016. Hasil penelitian ini menunjukkan struktur modal berpengaruh negatif dan signifikan terhadap kinerja keuangan, ukuran perusahaan berpengaruh positif dan signifikan terhadap kinerja keuangan, likuiditas berpengaruh positif dan tidak signifikan terhadap kinerja keuangan. Data yang dianalisis menggunakan regresi data panel. Berdasarkan analisis regresi data panel, dapat disimpulkan bahwa inflasi sebagai variabel pure moderating antara pengaruh likuditas terhadap kinerja keuangan.
\end{abstract}

Kata kunci: struktur modal, ukuran perusahaan, likuiditas, inflasi, kinerja keuangan

\section{PENDAHULUAN}

\section{Latar Belakang}

Setiap perusahaan berusaha untuk meningkatkan kinerja agar tujuannya dapat tercapai. Tujuan utama perusahaan adalah menciptakan nilai perusahaan melalui peningkatan kemakmuran pemilik atau para pemegang saham. Perusahaan dituntut untuk memiliki kinerja perusahaan yang baik serta mampu memanfaatkan sumber daya dengan efektif dan efisien untuk mencapai visi dan misi perusahaan. Oleh karena itu, selain berfokus pada laba jangka pendek, setiap manajer perusahaan perlu melakukan evaluasi kinerja.

Dalam melakukan evaluasi kinerja, dibutuhkan suatu pengukuran (measure) yang baik. Pengukuran kinerja merupakan salah satu faktor yang memegang peranan penting bagi perkembangan perusahaan. Hal ini dikarenakan pengukuran kinerja dapat digunakan untuk mengevaluasi performa perusahaan dan membantu perencanaan perusahaan di masa mendatang. Dengan kata lain, kinerja keuangan perusahaan dapat sebagai suatu pengukuran mengenai baik-buruknya perusahaan dalam prestasi kerja berdasarkan kondisi keuangan perusahaan. Industri Sektor Non Keuangan merupakan industri yang mendominasi perusahaan-perusahaan yang terdaftar di Bursa Efek Indonesia (BEI). Berbagai jenis industri di Indonesia memiliki tujuan yang sama yaitu untuk meningkatkan nilai perusahaan. Oleh karena itu, profitabilitas merupakan salah satu indikator dalam pengukuran kinerja keuangan suatu perusahaan. Profitabilitas yang meningkat menunjukkan kinerja perusahaan semakin baik, sedangkan profitabilitas yang menurun menunjukkan bahwa kinerja perusahaan memburuk. 
Penelitian mengenai pengaruh struktur modal, ukuran perusahaan, likuditas terhadap kinerja keuangan pada perusahaan non keuangan yang terdaftar di Bursa Efek Indonesia telah banyak dilakukan. Namun, hasil penelitian-penelitian terdahulu menunjukkan hasil yang berbeda-beda dan tidak adanya penelitian yang membuktikan bahwa inflasi memperlemah pengaruh likuiditas terhadap kinerja keuangan. Oleh karena itu, dilakukanlah analisis untuk menilai pengaruh struktur modal, ukuran perusahaan, likuiditas terhadap kinerja keuangan yang dimoderasi oleh inflasi pada perusahaan non keuangan yang terdaftar di Bursa Efek Indonesia tahun 2012-2016.

\section{Rumusan Masalah}

Seluruh makalah yang dikirimkan harap tetap menyertakan nomor halaman, dan header dan footer yang ada. Mohon header pada halaman genap disesuaikan judul makalah dan nama penulis. Jika nama penulis lebih dari satu, tambahkan "et al" untuk menggantikan nama penulis kedua dst.

\section{Kajian Teori}

Signalling Theory Menurut Brigham dan Houston (2016), sinyal merupakan tindakan yang diambil oleh pihak manajemen untuk memberikan arahan kepada para investor mengenai bagaimana prospek manajemen perusahaan. Pada kenyataannya, manajer seringkali memiliki informasi yang lebih baik dari investor (asymetry information), yaitu suatu kondisi dimana ada ketidakseimbangan perolehan informasi antara pihak manjamen sebagai penyedia informasi dengan pihak pemegang saham dan stakeholder sebagai pengguna informasi.

Pecking order theory menjelaskan mengapa perusahaan mempunyai tingkat keuntungan yang tinggi justru mempunyai tingkat hutang yang kecil. Sebuah perusahaan lebih menyukai pendanaan internal, artinya manajemen lebih memilih pembiayaan dari dalam perusahaan utnuk menambah kebutuhan modal

Trade off theory (Brigham dan Houston, 2016), menjelaskan pengaruh hubungan antara capital structure dengan nilai perusahaan terdapat satu tingkat yaitu leverage yang optimal. Penggunaan hutang akan meningkatkan nilai perusahaan sampai batas leverage yang optimal, dan penggunaan hutang yang melewati batas leverage optimal akan menimbulkan biaya kebangkrutan yang lebih besar.

Agency Theory Jensen dan Meckling (1976) menyatakan antara pemilik (principal) dan manajer (agent) mempunyai kepentingan yang berbeda. Adanya berbagai kepentingan ini, masing-masing pihak berusaha untuk memperbesar keuntungan bagi dirinya sendiri. Salah satu perbedaan kepentingan antara pemegang saham dan manajer antara lain maksimalisasi manfaat (utility) pemegang saham dengan kendala insentif yang diterima manajer. Hal ini menyebabkan konflik antara pemilik dan pemegang saham.

Kinerja Keuangan, Kimathi et al. (2015), kinerja keuangan didefinisikan sebagai berikut:. "A financial performance measure provides a valuable tool to stakeholders to evaluate the past financial performance and the current position of a firm." Kinerja keuangan merupakan sebagai alat pengukuran bagi pemangku kepentingan dalam melakukan evaluasi kinerja baik tahun sebelumnya ataupun tahun berjalan. Selain itu, Naser dan Mokhtar (2004) mengemukakan “A firm's high performance reflects its effectiveness and efficiency in the management of its resources for operational, investment and financing activities." Kinerja keuangan dapat mencerminkan kegiatan operasional, investasi, dan pendanaan perusahaan. Menurut Erasmus (2008) kinerja keuangan didefinisikan sebagai berikut: "Financial performance is the process of measuring the results of a firm's policies and operations in monetary terms." Kinerja keuangan adalah sebagai alat pengukuran kegiatan operasional perusahaan dalam bentuk 
satuan mata uang. Sehingga, dapat disimpulkan kinerja keuangan adalah suatu gambaran tentang kondisi keuangan suatu perusahan yang dianalisis dengan alat-alat analisis keuangan, sehingga dapat diketahui baik buruknya keadaan keuangan perusahaan. Ada beberapa faktor yang mempengaruhi kinerja keuangan, baik faktor internal maupun eksternal perusahaan. Faktor internal perusahaan memusatkan pada data-data laporan keuangan yang dianalisis sesuai kebutuhan. Hasil analisis laporan keuangan tersebut akan mencerminkan pengaruh struktur modal, ukuran perusahaan, dan tingkat likuiditas terhadap kinerja perusahaan. Sedangkan, faktor eksternal adalah faktor yang tidak dapat dihindari (uncontrolable) dalam setiap perusahaan. Dalam penelitian ini akan membahas mengenai pengaruh tingkat inflasi terhadap kinerja perusahaan.

Struktur Modal Menurut Karadeniz et al (2009) "Capital structure decision is one of the three decisions, alongside investment and dividend policy, which financial managers have to make with the objective of maximizing the value of the firm." Chadha dan Sharma (2015) menjelaskan bahwa "capital structure decision is a continuous process, whenever the firm requires funding for the project." Pandey (2005), menjelaskan "Financial leverage is the use of debt in a company's financial structure for magnification of earnings." Dengan demikian, struktur modal dapat didefinisikan sebagai salah satu keputusan pendanaan perusahaan dalam melunasi kewajiban perusahaan. Perusahaan mendahulukan pembayaran pokok hutang beserta bunga terlebih dahulu daripada kepentingan investor. Tingkat hutang yang semakin tinggi ini menyebabkan penurunan kinerja keuangan. Hal ini dikarenakan perusahaan berfokus dalam meningkatkan produktifitas untuk melunasi hutang tersebut (Lazar, 2016). Hasil Penelitian ini didukung oleh Seetanah et al.(2014), Dawar (2014), Demirhan et al. (2014). Sedangkan, menurut Zeitun \& Saleh (2015) menyatakan leverage berpengaruh positif terhadap kinerja keuangan. Hal ini dikarenakan ketika profitabilitas suatu perusahaan meningkat, maka perusahaan cenderung lebih menggunakan internal fund yang berasal dari laba ditahan. Hasil penelitian ini serupa dengan penelitian yang dilakukan oleh Fosu (2013).

Ukuran Perusahaan. Menurut Niresh dan Velnampy (2014), ukuran perusahaan didefinisikan sebagai "The size of a firm is the amount and variety of production capacity and ability a firm possesses or the amount and variety of services a firm can provide concurrently to its customers." Ukuran perusahaan dapat diukur melalui besarnya jumlah dan kapasitas variasi produksi serta jumlah pelanggan. Menurut Chandrapala (2013), ukuran perusahaan didefinisikan sebagai "size of the firm determines the level of economics of scale enjoyed by a firm. When a firm becomes larger it enjoys economics to scale and its average cost of production is lower and operational activities are more efficient." Semakin besar ukuran perusahaan, maka biaya produksi semakin rendah dan kegiatan operasional semakin efisien. Perusahaan yang besar memiliki akses untuk mendapatkan modal yang lebih mudah dibandingkan perusahaan kecil karena reputasi yang lebih baik dan biasanya memiliki jaminan atas pinjaman yang lebih besar. Besarnya jumlah pinjaman yang sesuai dengan yang dibutuhkan akan mempengaruhi kegiatan operasi perusahaan dan akhirnya mempengaruhi laba perusahaan. Hal ini didukung penelitian yang dilakukan oleh Muritala dan Ajibola (2014), Kuncova et al. (2016), Seetanah et al. (2014). Penelitian Lazar (2016) membuktikan bahwa ukuran perusahaan berpengaruh negatif terhadap kinerja keuangan. Perusahaan besar menyebabkan konflik antara manajer dan pemegang saham, karena adanya perbedaan kepentingan. Hal ini menyebabkan menurunya kinerja keuangan karena kurang adanya pengawasan dari manajer.

Likuiditas. Menurut Akenga (2015), "Liquidity refers to the ability of a firm to meet short term financial obligations by converting the short term assets into cash without incurring any loss." Pandey (2005) "a firm's liquidity is the ability of the firm to meet its 
short-term obligations; it is defined as the ratio of current assets to current liability." Likuiditas menunjukkan bagaimana perusahaan dapat memenuhi kewajiban jangka pendeknya. . Quick Ratio merupakan salah satu indikator likuiditas yang digunakan dalam penelitian ini. Rasio ini mengurangi persediaan dari sisi asset lancar karena persediaan tidak selalu dapat dikonversi secara cepat menjadi kas. Apabila perusahaan mampu melunasi kewajiban perusahaan dengan cepat, maka kinerja keuangan semakin bagus. Hal ini didukung penelitian yang dilakukan oleh Odalo dan Achoki (2016), Akenga (2015), Faroq (2012), Dermihan (2014). Penelitian tersebut membuktikan bahwa likuiditas berpengaruh positif terhadap kinerja keuangan. Sedangkan, berdasarkan penelitian Caporale et al. (2016), likuiditas berpengaruh negatif terhadap kinerja keuangan.Hal ini dikarenakan, karena adanya ketidakpastian dalam lingkungan yang tinggi menyebabkan likuiditas yang tinggi yang menyebabkan penurunan kinerja keuangan.

Inflasi Menurut Ahlgrim dan D'Arcy (2012), inflasi adalah "as changes in the overall level of prices within an economy, which consequently leads to fall in value of the domestic currency." Menurut Mirza dan Javed (2013) inflasi dedefinisikan sebagai "core annual inflation rate is taken to measure the impact of annual decline in the purchase power of currency". Menurut Guruswamy dan Hedo (2014), "Inflation is one of economic condition indicator which has impact on financial performance." Dengan demikian inflasi adalah salah satu faktor indikator ekonomi yang menyebabkan kenaikan harga barang. Laju inflasi yang tinggi menjadi beban bagi perusahaan untuk menghasilkan return bagi shareholders. Perusahaan harus mampu menghasilkan profit yang tinggi agar investor tidak melakukan divestasi atau menarik dananya yang akan mengakibatkan harga sahamnya turun dan membahayakan perusahaan. Inflasi yang meningkat mengakibatkan penurunan terhadap nilai ROA. Hal ini menjelaskan bahwa semakin meningkatnya inflasi akan mengakibatkan peningkatan suku bunga. Dengan demikian, perusahaan lebih cenderung menggunakan modal sendiri untuk membiayai kegiatan produksinya (Ogebe dan Patrick, 2014). Oleh karena itu, inflasi berpengaruh negatif terhadap kinerja keuangan.

Kerangka pemikiran dalam penelitian ini seperti digambarkan dibawah ini

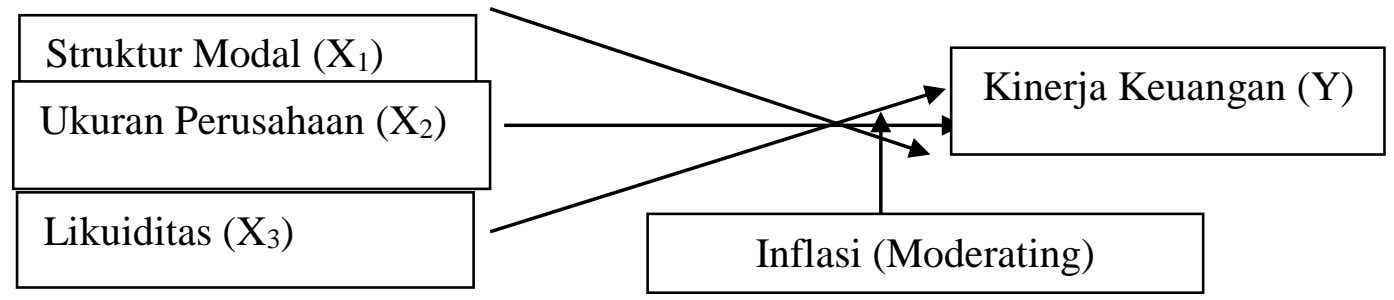

Gambar 1

Kerangka Pemikiran

Hipotesis dari model yang dibangun diatas adalah sebagai berikut;

$\mathrm{H}_{1}=$ Struktur Modal berpengaruh negatif terhadap Kinerja Keuangan

$\mathrm{H}_{2}=$ Ukuran Perusahaan berpengaruh positif terhadap Kinerja Keuangan

$\mathrm{H}_{3}=$ Likuiditas berpengaruh positif terhadap Kinerja Keuangan

$\mathrm{H}_{4}$ = Inflasi memperlemah pengaruh likuiditas terhadap Kinerja Keuangan 


\section{METODE PENELITIAN}

Objek Penelitian. Penelitian ini difokuskan pada seluruh perusahaan non keuangan yang terdaftar di Bursa Efek Indonesia pada tahun 2012-2016 yang laporannya didapat dari www.idx.co.id. Teknik pengambilan sampel yang dilakukan dalam penelitian ini adalah dengan menggunakan proportioned stratified random sampling, dengan kriteria-kriteria yang ditentukan dalam pengambilan sampel ini, yaitu: (a) Perusahaan Non Keuangan yang terdaftar di Bursa Efek Indonesia selama periode 2012-2016 (b) Perusahaan yang memiliki akhir tahun fiskal 31 Desember selama periode 2012-2016 dan sudah diaudit (c) Perusahaan yang mempublikasikan data-data selama periode 2012-2016 secara lengkap. Jumlah data yang memenuhi syarat sebanyak 168 perusahaan.

Variabel operasional dalam penelitian ini terdiri dari struktur modal, ukuran perusahaan, likuditas yang merupakan variabel independen, inflasi sebagai variabel moderating, dan kinerja keuangan sebgaai variabel dependen. Kinerja keuangan dalam penelitian ini diwakili oleh Return on Asset (ROA) yang membandingkan total pendapatan dengan total asset dengan formula:

$$
\text { ROA }=\frac{\text { Net Income }}{\text { Total Asset }}
$$

Stuktur modal dalam penelitian ini diwakili oleh Debt to Asset Ratio yang membandingkan total kewajiban dengan total asset dengan formula

$$
\mathrm{DAR}=\frac{\text { Total Liability }}{\text { Total Asset }}
$$

Ukuran perusahaan dalam penelitian ini diwakiliki oleh Log Natural Aset

$$
\text { SIZE }=\text { Log (Total Asset) }
$$

Likuiditas dalam penelitian ini diwakili oleh Quick Ratio

$$
\text { Quick Ratio }=\frac{\text { Current Asset }- \text { Inventory }}{\text { Current Liability }}
$$

Sedangkan, inflasi dalam penelitian ini diperoleh melalui indeks harga konsumen yang dapat diperoleh melalui www.bi.go.id. Dalam penelitian ini menggunakan uji statistik deksriptif untuk menguji sampel, uji moderated regression analysis, uji Robust Least Square. Sedangkan uji hipotesis menggunakan uji t dan uji koefisien determinasi

\section{HASIL DAN PEMBAHASAN}

\section{Hasil Uji Statistik Deskriptif}

Uji statistik deskriptif menggambarkan tentang ringkasan data penelitian seperti mean, standar deviasi, nilai minimum, nilai maksimum, sum, dan varians. Hasil statistik deskriptif untuk periode 2012 - 2016 menunjukkan bahwa kinerja keuangan memiliki nilai minimum sebesar -0.548465 , nilai maksimum sebesar 0.657201 , nilai mean 1.027670, dan standar deviasi sebesar 0.10315. Hasil statistik deskriptif untuk periode 2012 - 2016 menunjukkan bahwa Struktur Modal (DAR) memiliki nilai minimum sebesar 0.007416, nilai maksimum sebesar 5,365318, nilai mean sebesar 6.335565, dan standar deviasi sebesar 0.350840. Hasil statistik deskriptif untuk periode 2012 - 2016 menunjukkan bahwa Ukuran perusahaan (SIZE) memiliki nilai minimum sebesar 6.391990, nilai maksimum sebesar 8.597999, nilai mean sebesar 0,48063, dan standar deviasi sebesar 0.691822. Hasil statistik deskriptif untuk periode 2012 - 2016 menunjukkan bahwa likuiditas (Quick Ratio) memiliki nilai minimum sebesar 
3.029458, nilai maksimum sebesar 372.7801, nilai mean sebesar 2.955100, dan standar deviasi sebesar 16.20974. Hasil statistik deskriptif untuk periode 2012 - 2016 menunjukkan bahwa Rasio Kinerja Keuangan (ROA) memiliki nilai minimum sebesar 1,00 , nilai maksimum sebesar 1,11 , nilai mean sebesar 1,0321 , dan standar deviasi sebesar 0,02246.

Berdasarkan hasil penelitian yang dilakukan, maka peneliti mencoba memberikan pokok- pokok temuan penelitian secara keseluruhan. Hasil Analisis regresi data panel dapat disimpulkan dengan persamaan model regresi yaitu:

$$
\mathrm{Y}=0,002886-0,153907 \mathrm{X}_{1}+0,017656 \mathrm{X}_{2}+0,003481 \mathrm{X}_{3}-0.036889 \mathrm{X}_{3} \mathrm{X}_{4}+0.099910
$$

Dari persamaan diatas, nilai constant sebesar 0,102796. Hal ini berarti apabila variabel struktur modal, ukuran perusahaan, dan likuiditas sama dengan nol atau diabaikan, maka nilai kinerja keuangan adalah sebesar 0,102796. Uji Robust Least Square adalah uji yang digunakan asumsi yang mendasari prosedur tersebut tidak terpenuhi. Karena menggunakan Robust Least Square, maka asumsi klasik diperbolehkan diabaikan. Untuk menguji hipotesis nol ditolak atau diterima, titik tolaknya adalah bila nilai prob < atau > 0,05, artinya jika nilai signifikansi dari variabel independen di bawah 0,05, maka hipotesis diterima dan sebaliknya. Berdasarkan hasil pengolahan data, diketahui bahwa variabel struktur modal berpengaruh negatif dan signifikan terhadap kinerja keuangan, ukuran perusahaan berpengaruh positif dan signifikan terhadap kinerja keuangan, likuiditas berpengaruh positif dan tidak signifikan terhadap kinerja keuangan, dan inflasi memperlemah pengaruh likuiditas dan berpengaruh signifikan terhadap kinerja keuangan. Untuk mengetahui korelasi variabel-variabel independen terhadap variabel dependen, maka dilakukan uji koefisien determinasi $\left(\mathrm{R}^{2}\right)$. Berdasarkan hasil pengolahan data, didapatkan angka $\mathrm{R}^{2}$ sebesar 0.097611. Jadi, dapat disimpulkan bahwa 9,76\% varabel dependen dapat dijelaskan oleh variasi dari keempat variabel independen, sedangkan sisanya sebesar 90,24\% dapat dijelaskan oleh variabel-variabel lain diluar penelitian. Hasil uji ini dapat dilihat pada tabel dibawah ini.

Tabel 1

Method: Robust Least Squares

Uji Robust Least Square

Date: 01/06/18 Time: 15:38

Sample: 1840

Included observations: 840

Method: M-estimation

$M$ settings: weight=Bisquare, tuning=4.685, scale=MAD (median centered) Huber Type I Standard Errors \& Covariance

\begin{tabular}{lllll}
\hline \hline Variable & Coefficient & Std. Error & z-Statistic & Prob. \\
\hline \hline C & 0.002886 & 0.057549 & 0.050147 & 0.9600 \\
LEVERAGE (X1) & -0.153907 & 0.015842 & -9.715362 & 0.0000 \\
SIZE (X2) & 0.017656 & 0.008841 & 1.997139 & 0.0458 \\
LIQUIDITY (X3) & 0.003481 & 0.000785 & -4.435748 & 0.0520 \\
$\quad$ X3*X4 & -0.036889 & 0.009818 & 3.757334 & 0.0002 \\
\hline \hline & Robust Statistics & & \\
& 0.097611 & Adjusted R-squared & 0.090019 \\
\hline \hline R-squared & 0.294630 & Adjust Rw-squared & 0.294630 \\
Rw-squared & 1120.565 & Schwarz criterion & 1160.604 \\
Akaike info criterion & 3.985772 & Scale & 0.060011 \\
Deviance & 450.8038 & Prob(Rn-squared stat.) & 0.000000 \\
Rn-squared statistic & 450 &
\end{tabular}


Non-robust Statistics

\begin{tabular}{llll}
\hline \hline Mean dependent var & 0.046930 & S.D. dependent var & 0.103154 \\
S.E. of regression & 0.099910 & Sum squared resid & 8.304952 \\
\hline \hline
\end{tabular}

Hasil pengujian statistik dengan Robust Least Square menunjukkan bahwa variabel Struktur Modal berpengaruh negatif dan signifikan terhadap Kinerja Keuangan Hasil pengujian statistik dengan uji Robust Least Square menunjukkan bahwa variabel Ukuran Perusahan berpengaruh positif dan signifikan terhadap Kinerja Keuangan. Hasil pengujian statistik dengan uji Robust Least Square menunjukkan bahwa variabel Likuiditas berpengaruh positif dan tidak signifikan terhadap Kinerja Keuangan. Hasil pengujian statistik dengan uji Robust Least Square menunjukkan bahwa variabel Inflasi memperlemah pengaruh Likuiditas terhadap Kinerja Keuangan.

\section{KESIMPULAN DAN SARAN}

Berdasarkan hasil pengujian data dalam penelitian ini, hanya Rasio Likuiditas yang tidak memiliki pengaruh secara signifikan terhadap Kinerja Keuangan. Rasio Struktur Modal, dan Ukuran Perusahaan memiliki pengaruh terhadap Kinerja Keuangan.

Keterbatasan dari penelitian ini antara lain: (1) Pada penelitian ini periode pengamatan yang digunakan hanya lima tahun, yaitu dari tahun 2012-2016. (2) Pada penelitian ini hanya dilakukan sebatas variabel struktur modal, ukuran perusahaan, likuiditas, dan inflasi Berdasarkan hasil dan keterbatasan di atas, maka saran yang dapat diberikan untuk penelitian selanjutnya, antara lain: (1) Penelitian mendatang disarankan menambah periode penelitian, agar distribusi data menjadi lebih baik. (2) Penelitian mendatang sebaiknya menambahkan variabel-variabel independen lainnya, seperti growth, firm age dan faktor makro lainnya seperti tingkat suku bunga, nilai tukar rupiah.

\section{Ucapan Terima Kasih (Acknowledgement)}

Acknowledgement ini ditulis di bawah kesimpulan, sebelum referensi. Dalam acknowledgement ini disebutkan pihak-pihak utama yang mendukung penelitian ini, misalnya pemberi dana, instansi/orang pemberi data (dapat disamarkan apabila diperlukan anonim), asisten peneliti.

\section{REFERENSI}

Ahlgrim, K., D'Arcy, S.P. (2012). The Effect of Deflation on Insurance Industry Research Journal of Finance and Accounting. 4(2), 1-30.

Akenga, Grace (2015). Effect on Liquidity on Financial Performances of Firms listed at Nairobi Securities exchanges. International Journal of Science and Research, 6 (7):279-286

Ajija, Shochrul R. et al (2011). Cara Cerdas Menguasai Eviews. Jakarta: Salemba Empat. Ayako et al.(2017). Determinants of the Performance of Firms Listed At the Nairobi Securities Exchanges. Research Journal of Finance and Accounting, 6(12),157-166.

Bouckova, Marketa (2015). Management Accounting and Agency Theory. Procedia Economics and Finance, 25(2): 5-13.

Brigham, E.F. dan Houston, Joel F. (2016). Fundamental of Financial Management . Edisi Kesembilan. South Western College: Canada.

Caporale, Guglielmo Maria et al. (2016). The performances of banks in Mena Region during Global Financial Crisis. Journal of Economics and Finances, 10(2): 145158. 
Chadha, dan Sharma (2015). Determinants of capital structure: an empirical evaluation from India, Journal of Advances in Management Research,12 (1): 3-14

Chandrapala, Pathirawasam (2013). The Value Relevance of Earnings and Book Value: The Importance of Ownership Concentration and Firm Size. Journal of Competitiveness, 5 (2):98-108

Dawar, Varun. (2014). Agency Theory, Capital Structure and Firm Performance Some Indian Evidence. Managerial Finance Journal, 40 (2): 1190-1126.

Demirhan, H.Gökçehan, dan Anwar, Waseem (2014). FACTORS AFFECTING THE FINANCIAL PERFORMANCE OF THE FIRMS DURING THE FINANCIAL CRISIS EVIDENCE FROM TURKEY. Strategic Research Journal, 7(1):65-80.

Ebaid, Ibrahim El- Syaed (2009). The impact of capital-structure choice on firm performance: empirical evidence from Egypt. Journal of Risk Finance, 10(5): 477487.

Erasmus, P. D. (2008). Evaluating Value Based Financial Performance Measures, Corporate Ownership\& Control Journal, 6 (1): 66-77

Faroq, Omar (2012). Liquidity and Firm Performance in MENA Region, International Journal of Business Governance \& ethics, 7(3):82-95

Fosu, Samuel (2013). Capital structure, Product Market Competition, and Firm Performance: Evidence from South Africa. Review of Economics and Finance,53 (2): $140-151$.

Gantino, Rilla (2015). Effect of Managerial Ownership Structure, Financial Risk and Its Value on Income Smoothing in the Automotive Industry and Food \& Beverage Industry Listed in Indonesia Stock Exchange. Journal of Finance and Accounting, 6(4): 48-57.

Gujarati, Damodar dan Porter, Dawn C.. (2013). Dasar-Dasar Ekonometrika. Jakarta: Salemba Empat.

Guruswamy,D, dan Hedo, Abdulkerim (2014). Impact of Macroeconomic Variables on Financial Performance of Banks: A Case of Selected Private Commercial Banks in Ethiopia. Journal of Finances, 7(4): 19-24.

Hossain, Monzur, dan Rafiq, Farhana (2013). Global Commodity Price Volatility and Domestic Inflation Impact on the Performance of the Financial Sector in Bangladesh. Journal of Economics and International Finances: 1-25

Huber, Peter J. (1973). The 1972 Wald Memorial Lectures: Robust regression: Asymtotics, Conjectures and Monte Carlo, Journal of Applied Mathematic, Vol. 1 (5): 799-817.

Jensen, M. dan Meckling, W. (1976), Theory of the firm: managerial behaviour, agency costs and ownership structure, Journal of Financial Economics, Vol. 3, pp. 305-360

Judith, Modebe Nwanneka, dan Chijindu (2016). Dynamics of Inflation and Manufacturing Sector Performance in Nigeria: Analysis of Effect and Causality. International Journal of Economics and Financial Issues, 6(4): 1400-1407

Karadeniz, et al. (2009), "Determinants of capital structure: Evidence from Turkish lodging companies", International Journal of Contemporary Hospitality Management, 21 (5), 594-609.

Kimathi et al. (2015). Effect of Leverage on Performance of Non-financial Firms Listed at the Nairobi Securities Exchange. Journal of Finance and Accounting, 3(5). 132140.

Kuncova et al (2016). Firm Size as a Determinantof Firm Performance The Case of Swine Raising. Journal Economics and Informatics, 8(3): 77-90.

Lazar, Sebastian (2016). Determinants of Firm Performance: Evidence from Romanian Listed Companies. Review of Economic and Business Studies, 9(1): 53-69. 
Leland, Hayne E. dan Pyle, David H (1977). INFORMATIONAL ASYMMETRIES, FINANCIAL STRUCTURE, AND FINANCIAL INTERMEDIATION. The Journal of Finance, 32(2): 371-389

Mirza, Sidra Ali, dan Javed, Attiya (2013). Determinant of Financial Performance of a Firm: Case of Pakistani Stock Market. Journal of Economics and International Finances, 5(2): 43-52.

Muritala, TA dan Ajibola, O.B. (2014). Does Capital Structure Enhance Firm Performance? Evidence from Nigeria. Journal of Accounting and Audit Practiced, 12(4): 43-55.

Naser, K. dan Mokhtar, M. Z. (2004). Determinants of Corporate Performance of Malaysian Companies. Journal of Accounting, 4(2): 52-56

Niresh dan Velnampy, Thirunavukkarasu, (2014). Firm Size and Profitability: A Study of Listed Manufacturing Firms in Sri Lanka. International Journal of Business and Management, 9(4):57-65.

Odalo, Samuel Kanga, dan Achoki, George (2016). Liquidity and Financial Performance in Agricultural Firms listed in the Nairobi Securities Exchange in Kenya. International Journal of Business and Social Science, 7 (7): 57-65.

Ogebe, dan Patrick, Ojah (2014). the impact of capital structure on firm's performance in Nigeria. Journal of Economics: 1-24.

Ongore, Vincent Okoth, dan Kusa, Gemechu Berahnu (2013). Determinants of Financial Performances of Commercial Banks in Kenya. Economics and Finance Issue, 3 (1):237-252.

Pandey, I. (2005). Financial Management ( $9^{\text {th }}$ edition). New Delhi: Vikas Publishing House.

Ross, S. A. (1977). The Determination of Financial Structure: The Incentive Signaling Approach. Bell Journal of Economics and Management Science, 8 (1):23-40

Riaz, Saad (2015). Impact of Capital Structure on Firm's Financial Performance: Analysis of Chemical Sector of Pakistan. Journal of Poverty, Investment and Development: $85-95$

Roscoe, J.T. (1975) Fundamental Research Statistics for the Behavioural Sciences (2nd Edition). New York: Holt Rinehart \& Winston

Sarwono, Jonathan (2016). Prosedur- Prosedur Analisis Populer Aplikasi Riset Skripsi dan Tesis dengan Eviews. Jogjakarta: Gava Media.

Seetanah, et al (2014). Capital structure and firm performance: evidence from an emerging economy. The Business and Management Review, 4(4): 185-198.

Sekaran, Uma dan Bougie, Roger (2016). Research Method for Business: A Skill Building Approach. Edisi ketujuh.New York: John Wiley \& Sons, Inc.

Thorp, dan Quandt (1960). The new inflation. Financial Analysts Journal, 16 (6): 143 144

$\mathrm{Xu}$, Lei (2016). Governance and performance in China's real estate sector. Managerial Finance Journal, 6(1): 585-603.

Zeitun, Rami , dan Saleh, Ali Salman (2015). Dynamic performance, financial leverage, and financial crisis evidence from GCC countries. Journal of Business. Vol $10(2): 147-162$.

Undang-Undang Republik Indonesia Nomor 20 Tahun 2008 Tentang Usaha Mikro, Kecil, dan Menengah

www.saham ok.com

www.idx.co.id 